\title{
SEREIAS: UM ESTUDO FOTOETNOGRÁFICO SOBRE A MULHER NA ATIVIDADE PESQUEIRA NO ESTADO DO CEARÁ
}

\section{Sereias: a photoetnographic study on women in fishing activity in the state of Ceará}

\author{
Fernanda Cunha Oliveira ${ }^{1}$ \\ Geórgia Maria Feitosa e Paiva ${ }^{2}$
}

\section{http://dx.doi.org/10.52641/cadcaj.v7i1.655}

RESUMO: Ser mulher, preta, parda, indígena e nordestina constitui-se como uma coleção de fatores que podem desencadear preconceitos que refletem sobre as crenças sobre a capacidade humana e de trabalho do gênero feminino. A mulher nordestina é marcada pela luta e pelo empoderamento, que pouco a pouco ganha espaço nas atividades econômicas e sociais, como é o caso das "Sereias", pescadoras que sustentam seus lares nos municípios do litoral cearense. Este artigo tem como objetivo apresentar um estudo fotoetnográfico sobre o protagonismo feminino nas atividades de pesca no litoral cearense. Esse estudo teve início em 2012, com projeto fotoetnográfico apoiado pelo do Ministério da Cultura, Correios, Secretaria de Cultura do Estado do Ceará SECULT e Local Foto. Ao todo foram visitados sete municípios do litoral cearense conhecidos pela pesca artesanal de mariscos, algas e peixes. Por dois anos, tivemos a oportunidade de conhecer mulheres que protagonizam a cena pesqueira do Ceará, conhecemos suas casas, barcos, tradições, famílias e amigos. Quando imergimos no universo dessas mulheres fomos afetadas pelas suas histórias, que inspiraram esse relato.

Palavras-Chave: mulher; pesca; etnografia visual; relações de gênero.

\begin{abstract}
Being a black woman, with a mixed race, indigenous and northeastern is constituted as a collection of factors that can trigger prejudices that reflect on the beliefs about the human and work capacity of the female gender. A northeastern women are marked by struggle and empowerment, which little by little gains space in economic and social activities, as is the case of the "Sereias", fisherwomen who support their homes in the municipalities of the Ceara coast. This article aims to present a photoethnographic study on female protagonism in fishing activities on the coast of Ceará. This study started in 2012, with a photoethnographic project supported by the Ministry of Culture, Correios, Ceará State Department of Culture SECULT and Local Foto. In all, seven cities on the coast of Ceará were known for their artisanal fishing of shellfish, seaweed and fish. For two years, we had the opportunity to meet women who lead the fishing scene in Ceará,
\end{abstract}

1 Fernanda Oliveira é fotógrafa e pesquisadora. Coordenadora do Museu da Fotografia Fortaleza MFF 2017/2019.Mestra em Comunicação e Linguagens - linha Fotografia e Audiovisual pela Universidade Federal do Ceará UFC (2012) Professora Universitária - ministrou disciplinas nos cursos de graduação e pós graduação de universidades particulares e Federais em que também coordenou laboratórios e projetos. E-mail: fernandacoliveira345@gmail.com Orcid ID: https://orcid.org/0000-0001-7805-6029

2 Doutora em Linguística e Professora Adjunta do Instituto de Linguagens e Literaturas (ILL) da Universidade da Integração Internacional da Lusofonia Afro-Brasileira (UNILAB), Líder do Grupo de Estudos em Preconceito, Polidez e Impolidez Linguística (GEPPIL). E-mail: georgiafeitosa@,unilab.edu.br Orcid ID: https://orcid.org/0000-0002-2915-9416 
we know their houses, boats, traditions, families and friends. When we immersed ourselves in the universe of these women, we were affected by their stories, which inspired this story.

Key words: woman; fishing; visual ethnography; gender relations.

\section{INTRODUÇÃO}

O litoral brasileiro é um dos vinte maiores territórios banhados por mar em todo o planeta, somente no Estado do Ceará, há cerca de $573 \mathrm{~km}^{2}$ de extensão, área maior que alguns países da Europa, como Andorra e Malta. O litoral cearense é conhecido mundialmente pelas suas dunas, praias próprias para banho e sua fauna e flora marinha diversificada, que ora funde-se como fonte de sustento de diversas famílias cearenses, muitas vezes chefiadas por mulheres.

Segundo o Instituto de Pesquisa Estratégica Econômica do Ceará (IPECE), em pesquisa publicada em 2019, os lares cearenses chefiados por mulheres atingiram naquele ano a marca de 41,5\% dos municípios cearenses, tal índice apresenta uma tendência crescente nos últimos anos, fato influenciado pela qualidade e quantidade de anos de estudo que as mulheres vêm buscando cada vez mais, a fim de dirimir os cenários de desigualdade enfrentados na história. O estudo apontou que, apesar da participação feminina como gestora econômica familiar estar numa curva ascendente, a força do trabalho feminino ainda não é valorizada, recebendo uma renda inferior ao homem, mesmo este não tendo cumprido formação escolar semelhante.

No estudo publicado pelo IPECE (2021), no litoral cearense, as populações indígena e preta destacam-se sendo elas responsáveis importantes para o desenvolvimento econômico dos municípios com sedes nos litorais leste e oeste do estado. Muitas das atividades econômicas desempenhadas pelos municípios dos litorais leste e oeste do estado do Ceará são conduzidas por mulheres, que além de chefes de família, atuam como líderes de suas comunidades e inspiração para muitas gerações.

Deste modo, podemos dizer que o trabalho feminino é invisibilizado, desacreditado, quando muitas vezes atua de modo fundamental para a constituição da cultura familiar. Neste cenário, este artigo tem como objetivo principal apresentar um estudo fotoetnográfico sobre o protagonismo feminino nas atividades de pesca no litoral cearense. A ideia para a realização desta pesquisa surgiu a partir da experiência pessoal e afetiva com a praia e o mar, vivenciadas já na infância na posição de observadoras da cultura alheia ao urbano, que clamam as grandes capitais. A vida das mulheres do mar despertou a necessidade de adentrar suas realidades e de alguma maneira escrever suas histórias de vida pelas lentes da fotografia.

O Ceará por ser um estado de vasta faixa litorânea traz em sua gênese a cultura da pesca e do pescador, mas a pescadora é ignorada, mistificada, uma visão acanhada diante de uma realidade tão pungente. Essa constatação surgiu quando, ao participar de uma exposição em 2010 em meio a uma palestra do Festival Internacional de Fotografia Paraty conhecemos o trabalho de Roberto Linsker "Mar de Homens". Ali, naquele momento, o Terramar e os trabalhos desenvolvidos por eles se fez presente na memória como uma possibilidade de parceria para trazer ao cenário dos festivais a outra imagem do feminino, cuja voz e imagem estavam sendo negligenciados pela cena fotográfica. 
Para a realização desta investigação, balizada pelos pressupostos da etnografia visual, foram necessários quatro anos de estudo e imersão, o que culminou em 2016, o lançamento do ensaio e publicação do livro Sereias. Tudo isso foi possível com o apoio do Ministério da Cultura, Correios, Secretaria de Cultura do Estado do Ceará SECULT, Local Foto. Como instrumentos de investigação, foram usados como recursos uma câmera Canon Mark II e Go pro. A equipe era composta por Ângela Magalhães, Fernanda Oliveira, Iana Soares, Mika Holanda, Nadja Peregrino, Sérgio Carvalho e Tibico Brasil, que viajaram por todo o litoral cearense em busca das sereias.

Embora cearenses, a experiência proporcionada por esta pesquisa, nos fez conhecer sob outras lentes os sete municípios do litoral leste e oeste do estado do Ceará. Essa experiência imersiva desestabilizou estereótipos já fincados no imaginário das autoras, permitindo que este artigo, seja, antes de ser um relato investigativo, uma voz que representa um coletivo de mulheres.

\section{ETNOGRAFIA VISUAL: UM MERGULHO NECESSÁRIO}

A fotografia tem essa capacidade sui generis de aproximarmos um dos outros. Por meio da imagem podemos revelar a cultura de um povo, seus hábitos e costumes mesmo que não tenhamos estado lá. Por meio de uma técnica descritivo-interpretativa sobre a realidade social sob influência da subjetividade do pesquisador e também da subjetividade de quem ler a imagem - no caso o espectador.

O ser humano carrega em si o ímpeto de escrever sua própria história e isto acontece pensando sobre si e sobre o outro. Por identificação e estranhamento. É antes de tudo o processo de empatia, seja ele intencional ou espontâneo, que nos liga uns aos ouros.

As sociedades existem em seus contextos históricos, estéticos, políticos e a fotografia é construída e transformada por diferentes tempos. Na história da fotografia sempre o estigma da verdade e transparência, mas a complexidade que a cerca tira dela essa ingênua característica.

A etnografia tem por princípio a compreensão das sociedades e registro por meio de técnicas visuais e documentais. Mas dentre os gêneros fotográficos o estudo da cultura do homem é para mim aquele que mais se assemelha ao propósito de sua existência.

Para Achutti (1997) o problema central da antropologia é saber lidar e explicar as diferenças, as várias maneiras de viver. O levantamento dos dados etnográficos por meio do uso da imagem é sem dúvida uma forma genuína de enriquecer uma pesquisa. Os dados visuais não são mais para os etnógrafos uma mera cópia da realidade ou uma prova, descrição, acompanhamento do texto, mas o texto em si. Uma escrita visual diferenciada para interpretação do real vivido. A fotografia como ciência, um campo de pesquisa e escrita.

Os dados utilizados em pesquisa são consequência do trabalho de campo interpretativo do etnógrafo visual. É a experiência do pesquisador em campo, a proximidade com o homem e o bom uso da câmera para registrar seus costumes que possibilitam apuração dos dados. 
O tempo sem dúvida é um dos fatores constitutivos da excelência da pesquisa antropológica e etnográfica. Diferentemente de uma reportagem fotográfica que pode ser realizada pela rapidez do registro para construção de uma pauta e exigência de um resultado imediato para o fechamento de um veículo.

O trabalho de pesquisa na etnografia pede paciência e uma imersão na cultura a qual se quer compreender. Pois torna-se necessário a convivência, o experimentar de perto os hábitos ali registrado. Não é possível entender a realidade de uma sociedade sem que se permita ver, ouvir e aproximar do outro. "Não é uma antropologia da imagem, mas uma antropologia em imagens" como lembram Rodolpho et al.(1995, p.169, apud ACHUT'TI , p.39). Se o olhar é determinado pelo social, então de alguma forma o olhar sobre o outro é um encontro de olhares.

A utilização da câmera possibilita por meio do registro a análise posterior dos dados coletados, a imagem nos oferece um rico testemunho para o momento de análise e escrita. Por meio dos elementos contidos na fotografia podemos trabalhar com a interpretação dos fatos. A realidade percebida com o olhar fica apenas na memória humana e esta é frágil e vulnerável. O fixar dos aspectos de uma cultura na câmera deixa por escrito o lugar, a paisagem, as vestimentas, utensílios, gestos e rostos. São os aspectos da cultura da comunidade que está ali posta com suas variáveis a ser estudada e compreendida pelo pesquisador.

Para Collier. Jr:

A fotografia de ações sociais nos conduz a uma área rica de pesquisa não-verbal. Uma variedade considerável de ilustrações seguras desse campo pode ser observada através de fotografias de aspectos sociais, pois aí encontramos dimensões complexas de estrutura social, da identidade cultural e da expressão psicológica. Fotografias de pessoas que se aglomeram podem oferecer-nos oportunidades para avaliar, qualificar e comparar, porém estas avaliações podem ir muito além e auxiliar na definição da forma exata de cultura social. (COLLIER, JR. 1973, p. 49).

Fotografar a interação social nos traz ricos elementos para construção etnográfica. O pesquisador no trabalho de campo com o equipamento fotográfico fornece elementos que ajudam a analisar e descrever os grupos étnicos e estruturas sociais, os grupos e seus modus vivendi.

O inventário cultural torna-se rico pela escrita fotográfica apura detalhes para uso crucial da comparação e avaliação na pesquisa. Na imagem o registro que mostra os costumes, as cores, os objetos de uma dada comunidade.

A fotografia por mais simples que seja, independente do recurso tecnológico utilizado, nos oferece sempre uma gama de informações sobre o que se capta sobre o indivíduo. A capacidade de avaliar e identificar cientificamente dados de uma cultura dependem de elementos simples ou básicos fornecidos numa imagem. A foto-entrevista perpassa antes de mais nada o olhar do nativo é construído também pela interpretação que este tem de sua própria cultura. É no compartilhar de olhares que encontramos a construção de um foto-ensaio a ser realizado dentro de uma pesquisa qualificada. O fotógrafo por si só não 
deve realizar a interpretação da realidade do outro sem antes ouvir as experiências deste em sua comunidade e sem ver como eles se vêem. É na troca entre pesquisado e pesquisador que surge os elementos que compõem os dados de uma etnografia. Como esse homem se projeta em seu universo nos traduz seus hábitos e nos orientam em um caminho mais assertivo.

Collier afirma que:

Metodologicamente, a exigência da avaliação compreensiva de experiência de vida sugere a foto-ensaio como uma abordagem para descrição antropológica, usando todo o sentido e a habilidade do observador-fotógrafo. Quando montamos uma foto-entrevista para investigar os valores de vida dos navajos, estamos, na verdade apresentando um ensaio selecionado sobre a vida dos navajos, que compusemos, organizamos, para dar ao informante indígena uma oportunidade de falar sobre os valores e finezas de sua cultura. (Collier, Jr. 1973, pag. 72).

Geertz (2001) nos provoca com uma afirmação do filósofo Andy Clark, "Onde termina a mente e começa o resto do mundo? Onde termina a cultura e começa o resto do self? Se pensamos o indivíduo com suas vivências, sua constituição histórica, mas também com sua mente e emoções, compreendemos este mesmo indivíduo como um ser integral. Existe a individualidade de cada um, a experiência intrínseca, como cada ser cresce em sua cultura com suas particularidades; e existe dentro do universo de cada um, a soma de todos. É no conjunto de cada indivíduo que nasce o coletivo. Se assim pudéssemos afirmar que existe uma consciência coletiva construído na cultura. Uma forma de pensamento e de existência que oriunda da comunidade (comum-unidade).

Etienne Samain (2005) em seu texto nos lança uma reflexão sobre o "Olhar de Barthes e algumas reflexões lançadas à antropologia visual” as diferentes capacidades entre a foto e o cinema. Como a imagem fílmica por meio do orifício da câmera deixa uma imagem que já passou pelas imagens contínuas e como na fotografia a imagem se pôs através do orifício e ali permaneceu para sempre. Eles falam da foto contra o cinema. Penso que o uso distinto das duas formas de pensar imagem podem ser enriquecedoras para o uso da antropologia. De certo é para mim o uso da fotografia a melhor linguagem de se fazer pesquisa. É na imagem fotográfica que escrevemos sobre as culturas e buscamos representar o outro, permitindo ao público a possibilidade de criar conosco essa narrativa.

Conhecemos culturas pesqueiras sustentáveis que respeitavam a natureza, cujas mulheres se sobressaiam como líderes no enfrentamento a pesca industrial, a emancipação política e territorial que ainda desafiam os povos legítimos cearenses, índios, mulatos e negros. Nas próximas seções, apresentaremos as histórias das sereias cearenses. 


\section{A CULTURA DO OUTRO: AS HISTÓRIAS DELAS PELAS NOSSAS LENTES}

Para contar a história das Sereias do litoral cearense, foi muito importante firmar uma parceria com o Instituto Terramar - Instituição socioambientalista que tem como objetivo a busca pela justiça ambiental na zona costeira do Ceará. Eles desenvolvem projetos de acompanhamento e formação com as comunidades pesqueiras. Foi através da relação com o Terramar que foi possível coletar as principais informações que nortearam o projeto desenvolvido. A partir desta parceria conseguimos realizar um mapeamento das comunidades pesqueiras, as principais atuações pelo Estado, as mulheres que são líderes da pesca, os tipos de pesca artesanal distinguindo-se em pesca de marisco, pesca de alto mar, fazenda de algas e arrastão.

O interesse pela vida de outras mulheres, mulheres da praia, do mangue e do mar, e conhecer suas culturas, perpassa o fazer etnográfico enviesado pelo olhar da nossa infância, e ao escolher as mulheres pescadoras do Ceará, vimos na história de cada uma delas um pouco da nossa história com os mesmos cenários, mas neles somos coadjuvantes das musas inspiradoras, as Sereias ${ }^{3}$.

Eu olhava ali da beira da praia com os pés fincados na areia minha mãe e minha tia em cima da jangada de um pescador a entrar no mar. Vinha em mim a dubiedade de vê-las partir para o mar - o medo, a ansiedade e a incompreensão. Brotava também a admiração pela a ousadia, coragem e se lançarem ao imprevisível.

O interesse pela vida do outro, o adentrar a sua cultura, passa antes por mim. Ao escolher as mulheres pescadoras do Ceará vi ali na história de cada uma delas a minha história. Nasceu assim o projeto Sereias.

Durante toda a minha carreira estive viajando pelas cidades cearenses, conhecendo o meio rural, o sertão, o litoral e sempre com uma escuta atenta a cada experiência de vida narrada.

Foi no ano de 2001 que iniciei meus percursos fotográficos a convite de Organizações não governamentais (ONG's), institutos e instituições que visam pelo coletivo, para meios de comunicação (revistas e jornais) que retratavam o universo social desses povos. Daí nasce de uma forma quase que ocasional o interesse pela etnografia visual. ${ }^{4}$

\section{SEREIAS DOS RIOS E MANGUEZAIS}

Às margens do rio Jaguaribe, na cidade de Fortim, litoral leste cearense, abriga a pesca de mariscos, atividade econômica importante na região. Nossa primeira visita ao município foi no ano de 2012, quando

\footnotetext{
${ }^{3}$ Em entrevista com o Terra Mar e diálogo curatorial ficou determinado no Projeto que teríamos algumas mulheres personagens que tem destaque de liderança nessas comunidades. Nas fotografias todas as mulheres que nos foram apresentadas simbolizam o coletivo.

${ }^{4}$ Fragmento extraído do diário de campo produzido durante a pesquisa fotoetnográfica.
} 
tivemos contato com a primeira família de marisqueiros (marido, mulher e filhos) estavam na beira do rio, no manguezal separando as conchas que haviam coletado. Segundo a Prefeitura do local, o rio Jaguaribe é uma das principais fontes de renda dessas pessoas. Com uma extensão de $600 \mathrm{~km}$, o rio é responsável pela reprodução de peixes, moluscos e crustáceos. Rico em fauna aquática e terrestre agregando valor ecológico e econômico para o ambiente. Os mangues reproduzem 95\% do alimento que o homem pesca no mar.

Ao chegar em Fortim, buscamos na região a comunidade pesqueira, e foi atravessando um terreno por trás da casa de uma família, que encontramos uma senhora indicou alguns familiares que se preparavam para a coleta da pesca. O caminho em que atravessamos por dentro do mangue caminhando sobre uma ponte de madeira até chegar a beira do rio. Lá havia uma barraca de palha, um "fogão" com um panelão, uma mesa e alguns baldes. Nos baldes tinham os mariscos, eles separavam, peneiravam, as mulheres estavam trabalhando na mesa e separavam "o de comer" (ali mesmo almoçavam juntos) dos que levariam para vender aos atravessadores e restaurantes. Falaram que muitas vezes passavam uma manhã toda no sol, ou até mesmo o dia inteiro para conseguir coletar alguns poucos baldes e vendiam por cinco reais cada. Mas que nos restaurantes as pessoas pagavam caro para comer.

Ali, observando a separação dos mariscos, realizamos o primeiro contato da investigação fotoetnográfica, naquele momento foi pedida a permissão para acompanhar a rotina de trabalho, foi explicado sobre como seriam realizadas as fotos e que elas seriam publicadas em um livro. Falamos também sobre a exposição sobre o dia a dia deles, e que estávamos ali, porque o Terramar havia nos indicado. Naquele momento, dividindo o mesmo espaço, começávamos uma relação de confiança construída no decorrer das visitas pelos próximos anos.

No cronograma da pesquisa, estimamos que encontraríamos aquela família no mês seguinte, e assim fizemos. No encontro seguinte fomos numa canoa a motor para dentro do Rio Jaguaribe com uma mulher, seu marido e seus cachorros. Eles explicavam que o ofício da pesca era aprendido com as gerações anteriores e que esta era uma cultural familiar local. Ela explicava que o marido já pescava e que ela gostava apenas da pesca de marisco e preferia não ir ao mar.

Embora pareça uma atividade pesqueira menos perigosa, a pesca de mariscos requer destreza, e impõe a pele daqueles a realizam ulcerações. As mãos muitas vezes ficavam feridas por conta das conchas, ela relatava que o trabalho era penoso, debaixo de um "sol duro", mas que a beleza do lugar, a alegria do trabalho em conjunto com as outras famílias e o resultado para o sustento da casa era recompensador. "Aqui a gente trabalha, mas é a nossa diversão, passamos o dia no rio, tomamos banho, trazemos as crianças, cozinhamos e isso é a nossa vida. É daqui que a gente tira nosso sustento.”

Foram várias visitas nos meses seguintes nos anos de 2012, 2013 e 2014 a localidade de Fortim e seus arredores. Com o passar do tempo, o fazer etnográfico se tornava mais genuíno, proporcionando uma construção de vínculo, que permitiu conhecer a espontaneidade dos prazeres laborais de trabalhar às margens do rio. Na pesca do rio era frequente o mergulho e apneia usando utensílios como vara, bambu, peneira, óculos e snorkel. As mulheres mergulhavam com os homens e coletavam os búzios.

As mulheres mostravam papel de fundamental importância naquele grupo. Observava que elas de alguma maneira coordenavam as atividades, escolhendo os melhores locais, orientavam e ajudavam no 
grupo nas principais decisões. O homem, apesar de muitas vezes ficar com o trabalho de mais força física, não as impediam de realizar atividades que exigiam maior preparo físico. Era a força do trabalho coletivo que resultava na boa obra e bons resultados.

Um aspecto marcante da pesca no mangue é a pesca familiar. A presença da família era traço forte nesses grupos. Os animais domésticos, as crianças, os jovens, pais e vizinhos trabalhavam em grupo pelo equilíbrio socioambiental, respeitando os períodos de pesca, a natureza visando um retorno saudável para homem e natureza.

E podemos dizer que os laços familiares constituem os laços com a comunidade. Não muito longe do Fortim, no município de Aracati, conhecido pela famosa praia de Canoa Quebrada, conhecemos Cleomar, pescadora de mariscos do Cumbe (CE). Cleomar recebeu a equipe, e logo no primeiro contato, flagramos o seu trabalho político, atuando como representante das lutas das pescadoras naquela aldeia. Ela nos conduziu por um longo caminho de passeio no rio.

Sempre ao fotografar e olhar essas mulheres a sensação era mesma: da força feminina no trabalho e na vida familiar para além da luta social. Era ali que elas no simples trabalho que faziam dia a dia que estava o retrato do enfrentamento. Para nós pesquisadores, fotógrafos nunca será possível compreender o que essas comunidades vivem em sua rotina. São brigas por terra, pela natureza, pelo pão de cada dia, pelas famílias. Colocar-se no lugar delas, deles nunca será o suficiente para entender a dor e a resiliência dessas pessoas. A fotografia toma posse de uma realidade que não é nossa, busca e tenta compartilhar essas realidades, mas me parece que nunca bastará. A empatia em situações como essa ainda me parece um gesto inatingível. Porque ao acompanhá-los um dia na pesca de arrastão, fomos para a praia. E ao chegar lá, tínhamos que passar pelo portão do parque eólico e o guarda (porteiro) quis impedir a entrada dos pescadores (ras).

Houve uma discussão para que fosse autorizada a entrada deles. Acredito que pela presença da câmera, dos fotógrafos eles evitaram, naquele momento, incitar alguma confusão e permitiram a nossa entrada. Mas ali estava uma realidade que eles vivem com frequência. E quando não estamos lá? E se não houver registro? E se não houver denúncia? E se não houver institutos que lutem por eles?

As fazendas de camarão, segundo as pescadoras, trazem grande prejuízo ao rio. Elas me mostravam em suas mãos a proliferação de algas que matavam os peixes. Explicavam como aquela situação era nociva para todo o dinamismo socioambiental. E apesar de tudo, elas trabalham com o sorriso no rosto, com a alma íntegra resplandecendo a dignidade de seus trabalhos.

\section{SEREIAS DA PRAIA}

Em 2013, fui explorar em Acaraú, litoral oeste do Ceará a comunidade pesqueira do Curral Velho, com apenas quatro mil habitantes que vivem da pesca artesanal (mariscos e curral). Vimos os currais de 
pesca montados à beira mar, os currais são construídos em maré baixa na zona da praia, são como paredes construídas com cercas de madeiras e redes. Ao subir a maré os currais detêm os peixes e na baixa maré os pescadores entram em seus labirintos de currais para colher a pesca.

Observando aquela construção artesanal de pequenos cárceres amontoados em meio a sensação de liberdade que o oceano nos traz, conhecemos um casal, que esperava os peixes caírem nas armadilhas. Enquanto fotografávamos, perguntamos pela família e como se dava o hábito da pesca naquele local. Eles me explicaram que "ali era mais eles dois mesmo". Os outros moradores, mas que alguns dos jovens não tinham interesse na pesca, mas se envolviam com outras atividades do lugar. Muitos tinham um interesse maior em estudar e não necessariamente em desenvolver o mesmo ofício. Naquele dia me pareceu ao contrário de Fortim um momento solitário, talvez por causa do dia ou horário da visita.

$\mathrm{Na}$ ida seguinte ao local conheci as casas construídas pela comunidade para reuniões do projeto e recepção de pessoas a Acaraú. Nesta casa aconteciam reuniões para discutir as ações a serem realizadas e formação para a comunidade. O sentimento de pertença ao lugar me parece uma assinatura autêntica nessas comunidades pesqueiras. Uma afirmação identitária por parte de seus moradores. Eles lutam pela terra e pelo o que dela provém.

Essa luta de classes se estende por essas associações e grupos pesqueiros. No ano de 2013, em visita a praia de Maceió - Itapipoca (CE), sem nenhuma programação prévia, contactamos os líderes da comunidade e avisamos de que estaríamos lá para conhecê-los e explicar o projeto. Quando pensamos que os surpreenderíamos com a visita sem convite, nos surpreendemos quando chegando lá, pois nos assentamentos de Maceió estava naquele momento havendo uma reunião do Movimento Sem Terra MST. O MST tem como busca principal a conquista da terra e reforma agrária, direitos básicos como moradia, trabalho, cultura, lazer e pertencimento. As familias assentadas organizam-se por uma sociedade estruturada com base na coletividade. Os moradores de Maceió estavam juntos discutindo as ações necessárias. Lá estavam as famílias, pescadores e pescadoras, idosos, crianças, artesãs locais com suas almofadas a tecer rendas de bilro. O povo estava inflamado, discutiam, falavam alto e alegres. Era contagiante o ambiente. Eles pautavam as reinvindicações que iriam fazer na próxima reunião com as instituições parceiras e secretarias, um dia inteiro para estruturar as decisões para as melhorias locais.

Naquele momento começamos a fazer retratos dos presentes, para além das outras formas de fotografia. As vulnerabilidades ali juntas buscando no coletivo a força do empoderamento nos inquietou de tal modo, que para além das mãos que fazem a pesca, nos focamos nos rostos, nas faces que lutam. Fotografias simples que em muito poderiam mostrar a identidade de cada um ou mesmo de todos - como uma familia.

Maceió nos mostrou uma pesca sustentável, a pesca e cultivo de algas, a vegetação que sazonalmente toma as praias, também é insumo de produtos alimentícios e cosméticos. Para pescar algas, os pescadores confeccionam redes especiais e as instalam no mar, na zona de arrebentação, são redes com cordões delineando o percurso do cultivo. Com um paquete eles entram até o local das redes, recolhem as algas mergulhando e retirando para a terra. Em frente ao mar fica a casa de trabalho do assentamento em que há no terreno umas mesas de varais e telas para secagem das algas expostas a luz solar, uma casa de estoque 
para guardar as algas e fazer a separação do material. As mulheres do Maceió são referência no trabalho rural desde a confecção das redes até a separação dos insumos marinhos.

\section{SEREIAS DO MAR}

Entre os anos de 2014 e 2015, pudemos conhecer mulheres que pescam em alto mar. Em Redonda, praia de Icapuí (CE), região leste, conhecemos Sidnéia. Segundo orientação do instituto naquele momento havia quatro mulheres que realizavam a pesca de alto mar com perfil de liderança para compartilhar suas experiências. Em Redonda, acordamos as 3 h00 da manhã para ir mar adentro com Sidnéia e seus companheiros de pesca. Um barco a vela que levou algumas horas para atravessar a faixa litorânea. Neste dia não tivemos tanto êxito na pesca, mas foi possível acompanhar o trabalho deles em alto mar. Lá em direção ao horizonte eles pararam o barco e junto com eles mergulhei no mar. Meu medo: tubarão. Ela me disse: estamos em alto mar, aqui é o habitat deles, mas você não tem que ter medo não. Você sabe nadar. Então você fique tranquila que aqui eles são bem alimentados.

Passamos a manhã ali - eu nadando no mar com a câmera fotográfica (bolsa estanque) e go pro na mão. Apesar dos pescadores no barco, meu foco estava nela. Entender como uma mulher tinha a valentia e a coragem de entrar em alto mar com aqueles homens. Ela fazia o trabalho pesado tanto quanto eles. Com forte perfil de liderança e técnica pesqueira. Ela me contou que sofreu desde criança preconceito na aldeia por parte dos moradores por querer pescar no mar. Muitos da comunidade lançavam sobre ela apelidos e não compreendiam a sua escolha de trabalhar num universo essencialmente masculino, pois a pesca de alto mar exige esforço, força, coragem e determinação.

Para Allport (1979, p.7), o preconceito consiste em "uma atitude aversiva ou hostil face a uma pessoa pertencendo a determinado grupo, simplesmente por causa da sua pertença a esse grupo, e em que se pressupõe que esta possui as características atribuídas a esse grupo". Para o autor, os indivíduos podem ter preconceito com relação a grupos baseados em: raça, sexo, níveis etários, grupos étnicos, regionais, religiosos, nacionais, ideológicos, castas, classes sociais, profissionais, níveis educacionais, grupos de interesses, além dos modos de falar, grupos linguísticos.

Quando decide passar dias no mar, o barco torna-se a sua casa, lugar de empoderamento. Eles dormem, comem, trabalham e fazem suas necessidades ali. Para ela isso não foi impedimento. Sidnéia conta que desde cedo insistia em ir ao mar com o pai. Que aprendera a pescar com aqueles homens e que muitos foram contra a sua insistência. Mas que ela tinha uma atração e amor pelo mar maior do que os preconceitos que enfrentara. Ela acabou por se firmar na sua comunidade pela excelência do trabalho e pela coragem. Sid (como costuma ser chamada por todos) tem a aparência física forte, uma mulher escultural, com braços torneados e pernas resistentes - certamente pela consequência de lida diária.

Com o seu trabalho ela conseguira construir uma pousada na praia para além da pesca: uma mulher com caráter empreendedor. Fala o que pensa, não tem meias palavras, se afirma diante do grupo e faz o que quer. Dessa maneira foi conquistando seu espaço e respeito. Ela esteve em matérias de jornais, revistas e 
documentários pelo destaque de seu trabalho e personalidade. Algo que se destaca no relato da pescadora é que ela se diferenciava das demais mulheres de sua vila porque gostava de jogar futebol e pescar com os homens do lugar. Isto para ela pareceu marcante na sua história de vida: o enfrentamento aos preconceitos de uma cultura machista no interior do estado. Mas para ela nada disto impediu seu sonho de vida e talento. Sid é mostrada nas imagens como uma autêntica Sereia. Seu corpo vivo no mar, os detalhes de seus movimentos, sua respiração, seus braços e suas pernas. Explorar a imersão de seu Ser mar. O que aflorava em sua essência uma mulher inteira em comunhão com o universo marinho.

Não muito longe de casa, em Fortaleza, conhecemos Maria Cabelão. A pioneira da pesca no estado do Ceará. Dona Maria foi a primeira mulher a entrar no mar para pescar. Com a ajuda de seu pai e familiares era aprendeu a arte da pesca. Ainda nova, com ousadia ela acompanhou os homens de sua família no mar da Beira-mar em Fortaleza, na praia do Mucuripe.

Maria Cabelão mora no Morro de Santa Terezinha próximo ao mar. Antigamente quando o Morro ainda estava em seu início com poucas casas construídas pela PROAFA - Fundação Programa de Assistência as Favelas, o Programa do Governo para os pescadores que moravam na enseada do Mucuripe na beira da praia e vivenciaram o despejo recebendo do Estado novas casas no Santa Terezinha Morro em frente a praia do Mucuripe.

Dona Maria Cabelão fala sobre como a pesca foi sua principal atividade e fonte de renda durante toda a sua vida. Idosa já não exerce mais o ofício. Um mulher de sorriso e temperamento forte, um jeito incisivo de falar, às vezes quase teimoso, traz consigo uma característica cearense pela maneira sincera de tudo dizer.

Ao chegar em sua casa apresentamos o projeto, expliquei sobre as fotografias e documentação das pescadoras. Ela retrucou: não, não quero falar com ninguém não. Mas pra que é esse projeto aî? ... Convidou para entrar em sua casa, fomos conversando, ela foi apresentando a sua família, e foi cedendo. Ofereceu café, disse que seria falta de educação não tomar e já foi logo colocando no fogão a água pra ferver. Depois mostrou o quintal e apresentou com muita alegria o seu papagaio. Logo muitos sorrisos foram brotando a partir de nossas conversas e ela foi se deixando fotografar. Até mesmos retratos, poses e com um sorriso intenso para câmera. Ela falou um pouco do altar em sua varanda a Nossa Senhora e de sua fé. E que sem Deus nada poderia. Para ela a vida era muito difícil, mas sempre com a certeza de que tudo que tinha conquistado tinha sido com a força de seu trabalho, sua rotina pesada e cuidado de Deus. Ela mostrou uma coleção de fotos que outros fotógrafos fizeram dela ao visitarem sua casa, matérias de jornais e entrevistas. Ao fotografar Maria Cabelão compunha as cores de um azul intenso e saturado da parede de sua casa, trazendo na imagem o azul do mar. De como aquele azul representava sua identidade e história. A cor saturada denotava para mim o traço de sua personalidade. Nos retratos de Maria Cabelão registrava a sua alegria, seu bom humor e intensidade.

Em 2016, pouco antes de concluir as nossas viagens etnográficas, visitamos novamente a praia de Canoa Quebrada (CE). Na ocasião, conhecemos Márcia, mulher de sorriso largo e alegria singular. Márcia conheceu seu esposo que já exercia a pesca no mar, ao se mudarem para a cidade de Canoa, ela aprendeu a atividade pesqueira com o seu marido. Márcia fala da paixão que desenvolveu pelo mar e que isto tornara- 
se a coisa mais importante de sua vida. Seu marido disse que se deixasse ela o abandonava pelo mar. E que sempre a acompanhava para segurar a esposa. Perguntamos se ela tivesse que escolher entre ele e o mar. Ela respondeu: o mar. E que se pudesse construía uma casa no mar para morar. Que só voltava porque não tinha outra escolha.

Fomos juntos num paquete pelo mar, juntos eles tinham uma sintonia de trabalho, era perceptível o companheirismo. Na escolha do enquadramento da fotografia busquei retratar o imaginário de Márcia de “morar no mar", em que o barco era casa e casa n’água. Nas próximas páginas, seguem as imagens do ensaio, da pesquisa e considerações finais. 

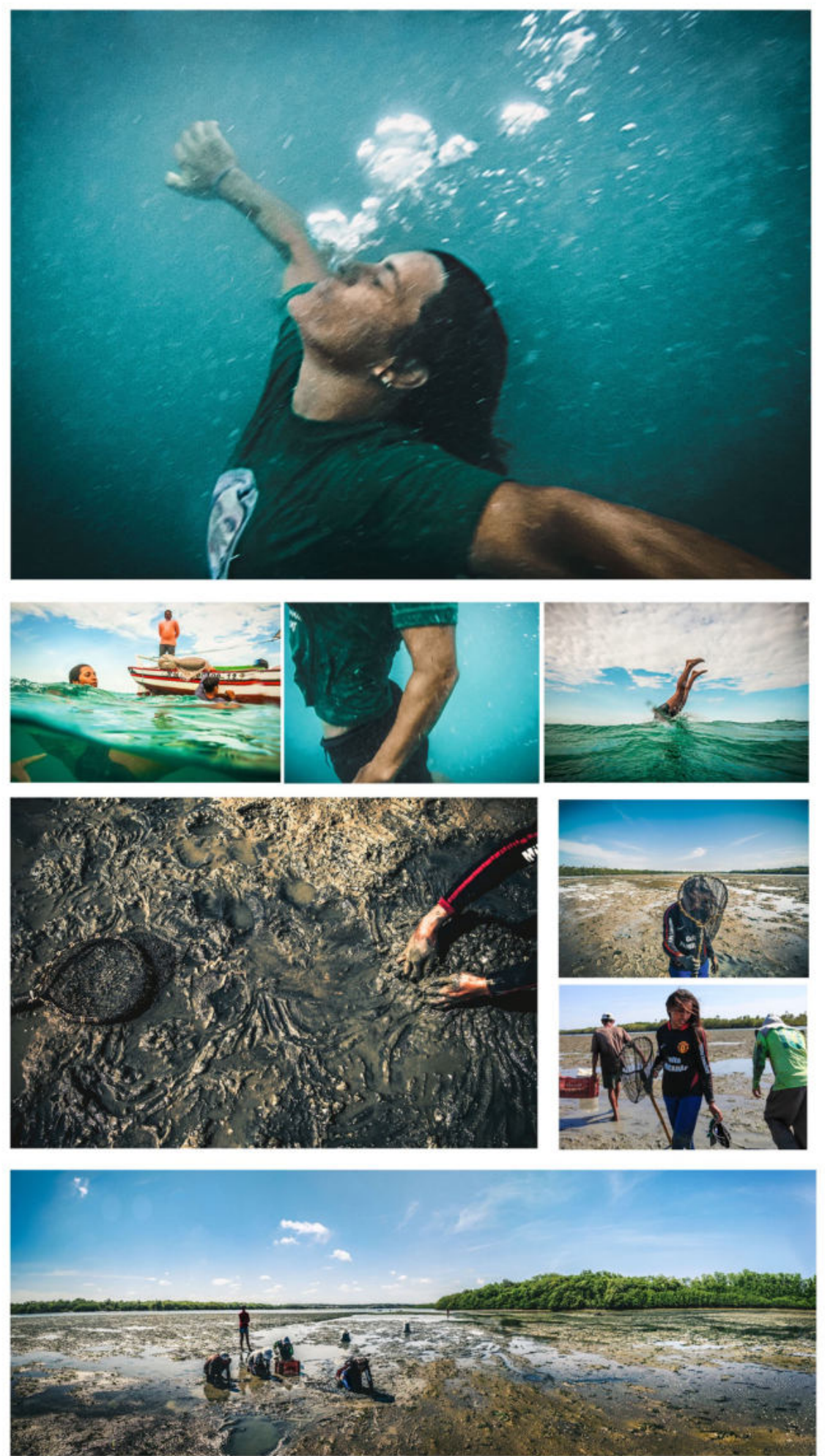


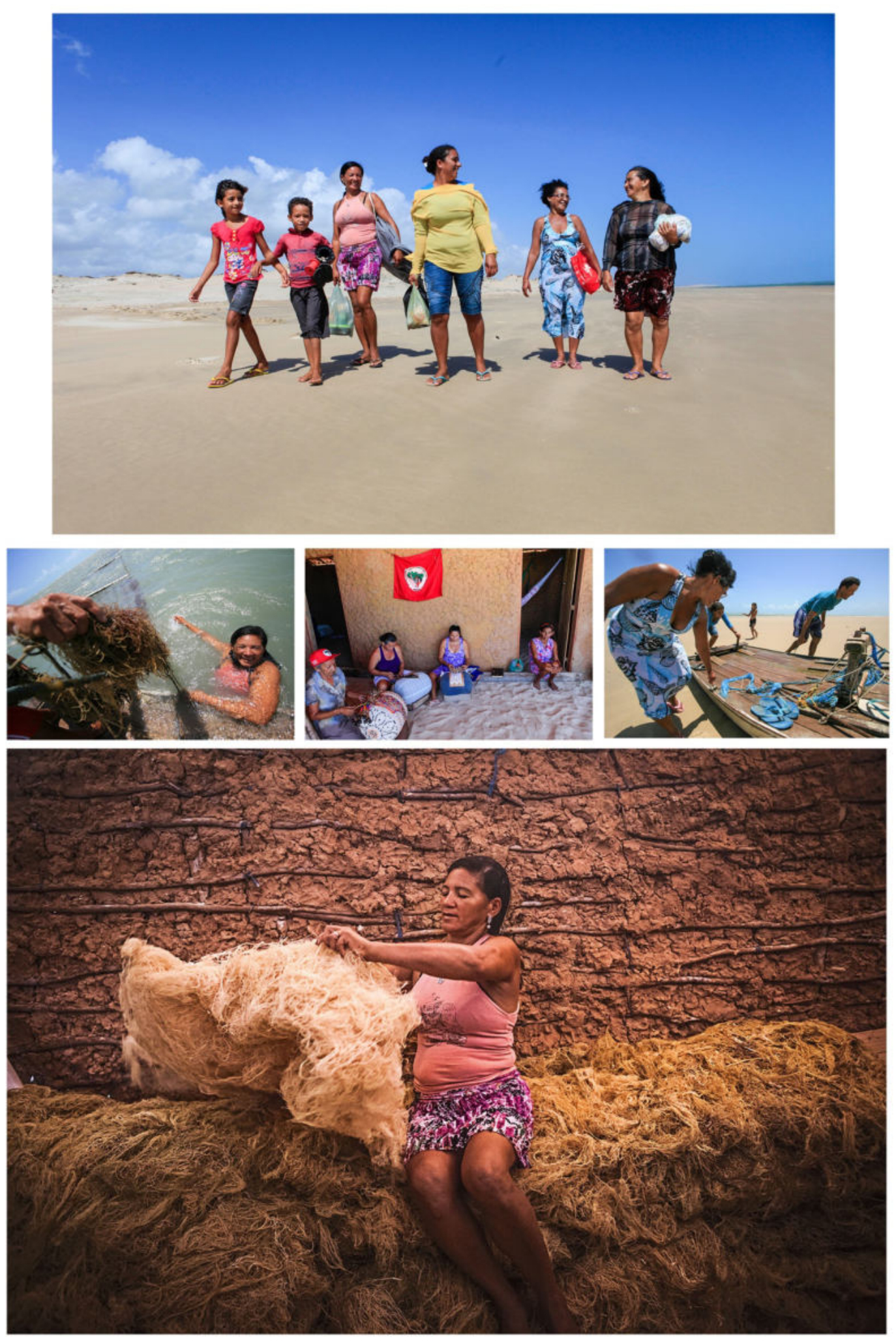



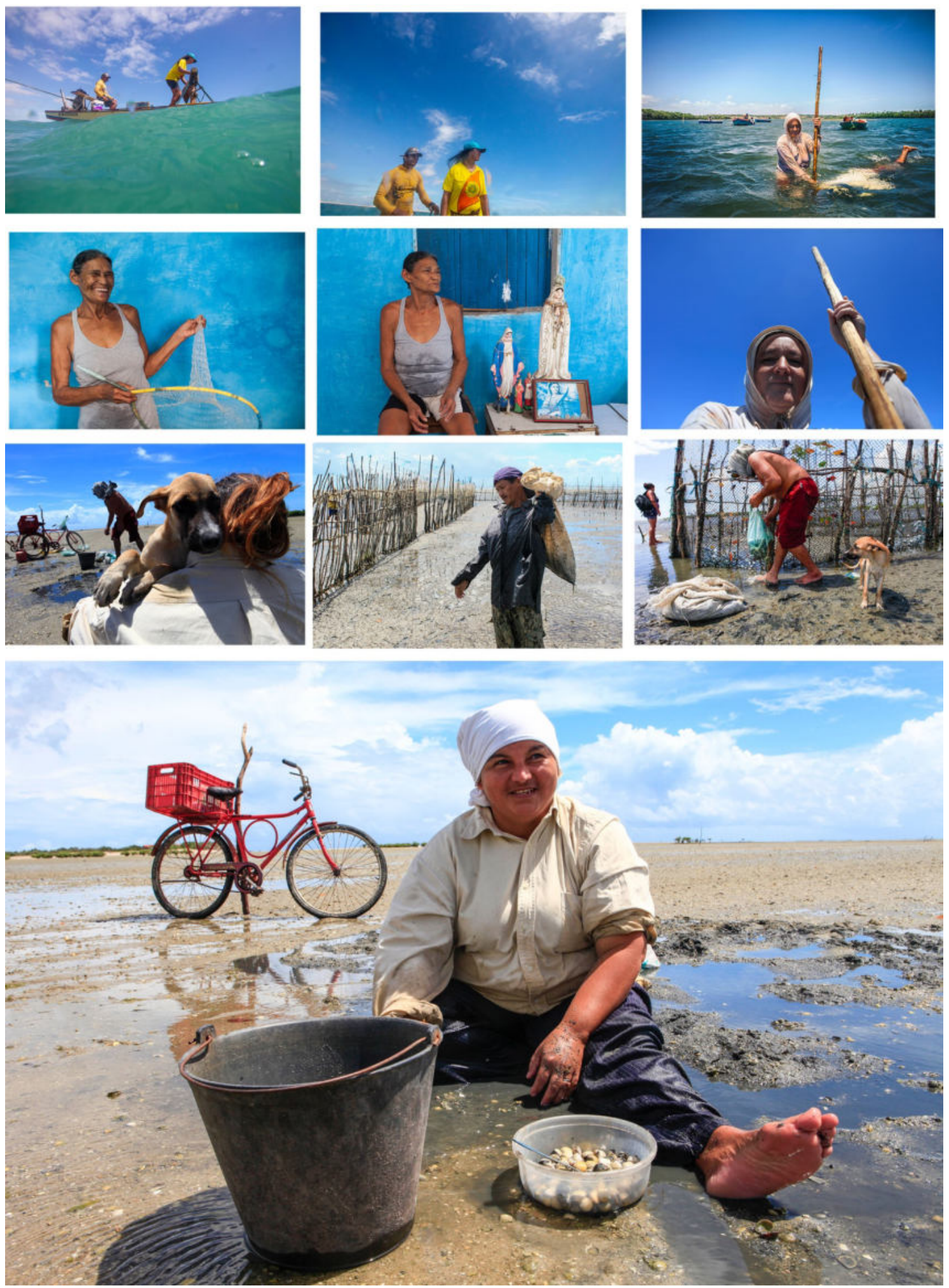

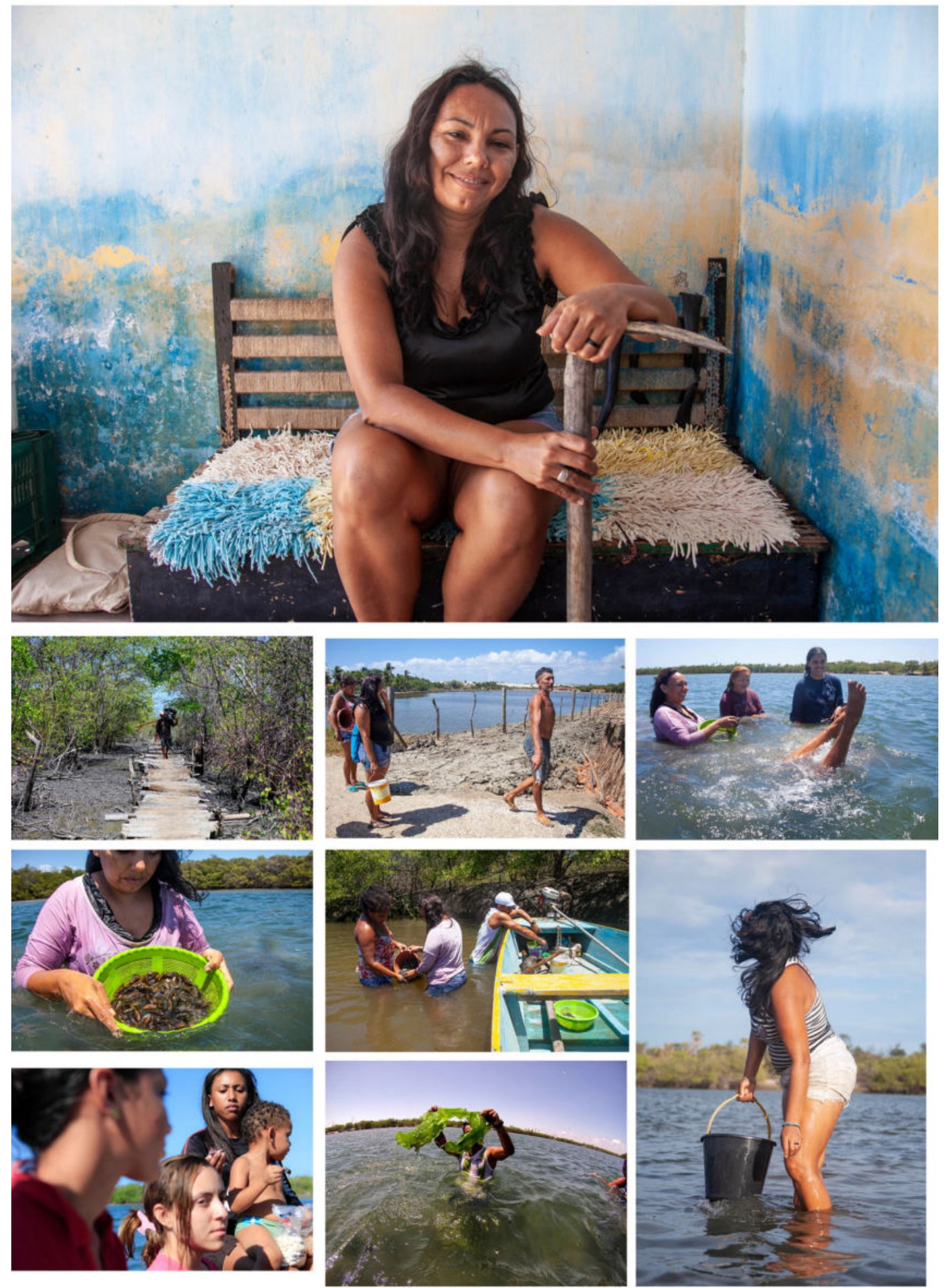

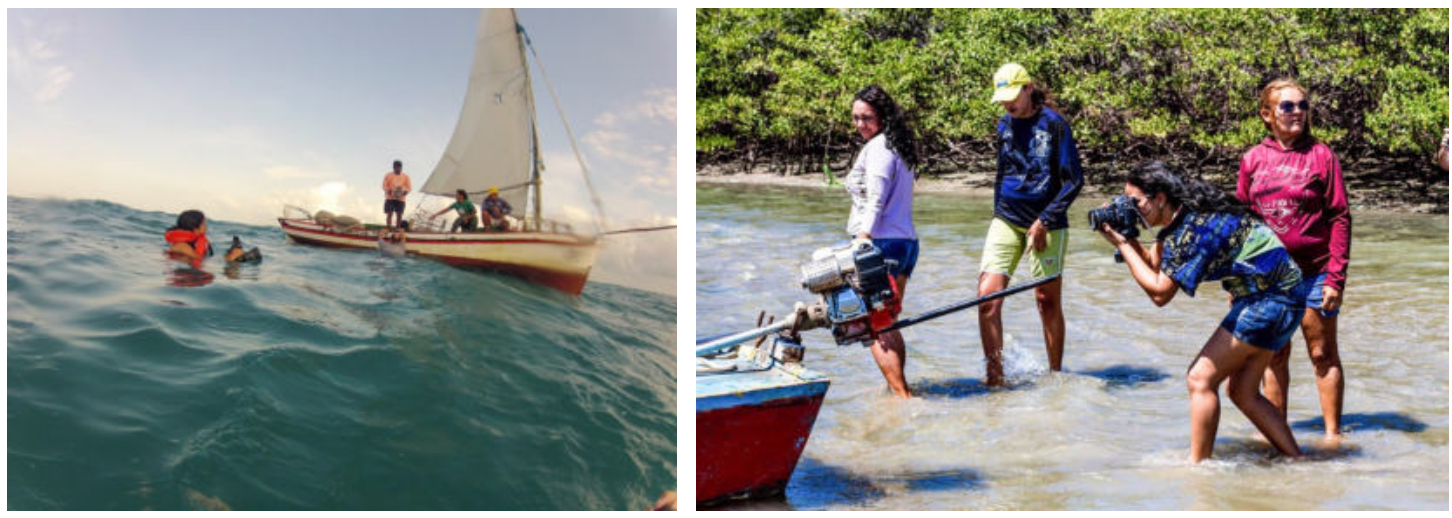

\section{CONSIDERAÇÕES FINAIS}

O fotógrafo ao entrar numa comunidade de vila de pescadores observa a dinâmica social do local, os tipos de roupas que os moradores e trabalhadores usam, os tipos de barcos de pesca, a economia, se a pesca é apenas para subsistência ou comércio, o impacto sobre o grupo através da atividade pesqueira, como as gerações familiares se definem por meio do trabalho, a participação desta família no trabalho de grupo, os utensílios utilizados, a relação com o meio ambiente, suas crenças e como isso interfere no comportamento coletivo, etc.. O diálogo, que vai além de uma experiência comunicativa, torna-se parte de uma experiência estética que permite que fotógrafo e comunidade se deixem conhecer pela câmera, que se encarrega de dar o tom a experiência vivida.

$\mathrm{Na}$ construção do ensaio nunca buscamos uma atmosfera de denúncia, contudo, encontramos nessas mulheres uma dignidade que quis ser a assinatura fotográfica desse olhar. A presença delas, os gestos, o modo como se lançavam no mar, nos mangues, nos rios nos inspiravam, e nos lembravam que elas eram sinônimas de força, caráter, sororidade, alegria e a determinação e paixão com que cada uma delas exercia seu trabalho.

Quando o projeto se tornou livro e exposição, sentimos que aquelas imagens estavam falando por elas, lutando com elas, agindo, transformando. Foi aí que percebemos que as Sereias de carne e osso ali estampadas nas paredes de uma exposição possibilitaria mais espaço para que o projeto conquistasse lugares em que a voz delas tivesse eco. Assim, a fotografia seria a ponte para que elas fossem vistas. Se revelava ali a áurea fotográfica reafirmando a identidade delas. O objetivo era compreender o universo dessas mulheres e da pesca artesanal, mas fomos afetadas, nunca mais fomos as mesmas. 


\section{Referências}

ALLPORT, Gordon W. The nature of prejudice. New York: Basic books, 1979.

ACHUTTI, Luiz Eduardo Robinson. Fotoetnografia: um estudo de antropologia visual sobre cotidiano, lixo e trabalho -Porto Alegre. Tomo Editorial; Palmarinca: 1997.

COOLIER, John. Antropologia Visual: a fotografia como método de pesquisa; tradução FERRAZ, Iara ; COUCEIRO, Solange Martins. São Paulo, EPU, Ed. Da Universidade de São Paulo, 1993.

ETIENNE, Samain - organizador. O fotográfico. $2^{\mathrm{a}}$ edição, São Paulo: Editora Hucitec/ Editora Senac São Paulo, 2005.

GEERTZ, Clifford. Nova Luz sobre a antropologia/ Clifford Geertz; tradução, Vera Ribeiro; revisão técnica, Maria Cláudia Pereira Coelho. - Rio de Janeiro: Jorge Zahar Ed., 2001.

IPECE-CE. Instituto de Pesquisa Estratégica Econômica do Ceará. IPECE informe / Instituto de Pesquisa e Estratégia Econômica do Ceará (IPECE) / Fortaleza -Ceará: Ipece, 2021 .Disponível em: https://www.ipece.ce.gov.br/wpcontent/uploads/sites/45/2021/01/PRAD informe N02 28 jan2021.pdf (Acesso em: 19 de abril de 2021)

FORTIM, Prefeitura Municipal de Fortim (Ceará). Dados sobre atividades sociais e econômicas no Município de Fortim. Fortim, 2021. Disponível em: https://www.fortim.ce.gov.br/informa.php?id=13 (Acesso em: 22 de maio de 2021)

TERRAMAR. Instituto Terramar. Quem somos nós. Disponível em: http://terramar.org.br/sobre-nos2/quem-somos/ (Acesso em: 22 de maio de 2021)

MST. Movimento Sem Terra. Quem somos nós. Disponível em: https://mst.org.br/quem-somos/ (Acesso em: 22 de maio de 2021)

ECONORDESTE. Projeto resgata e valoriza tradição de renda de bilros no Ceará. Disponível em: https://agenciaeconordeste.com.br/projeto-resgata-e-valoriza-tradicao-de-renda-de-bilros-no-ceara/ (Acesso em: 22 de maio de 2021)

PGE-CE. Procuradoria Geral do Estado do Ceará. Projeto de cultivo de algas será inaugurado no assentamento Maceió em Itapipoca. Disponível em:https://pgece.jusbrasil.com.br/noticias/1995647/projeto-de-cultivo-de-algas-sera-inaugurado-no-assentamentomaceio-em-itapipoca (Acesso em: 22 de maio de 2021) 